\title{
Cluster observations of bounday layer structure and a flux transfer event near the cusp
}

\author{
R. C. Fear ${ }^{1}$, A. N. Fazakerley ${ }^{1}$, C. J. Owen ${ }^{1}$, A. D. Lahiff ${ }^{1}$, E. A. Lucek ${ }^{2}$, A. Balogh ${ }^{2}$, L. M. Kistler ${ }^{3}$, C. Mouikis ${ }^{3}$, and \\ H. Rème ${ }^{4}$ \\ ${ }^{1}$ Mullard Space Science Laboratory, University College London, Holmbury St. Mary, Dorking, Surrey, RH5 6NT, UK \\ ${ }^{2}$ Blackett Laboratory, Imperial College of Science, Technology and Medicine, Prince Consort Road, London, SW7 2BZ, UK \\ ${ }^{3}$ Space Science Center, University of New Hampshire, Durham, NH 03824, USA \\ ${ }^{4}$ CESR/CNRS, 9 Avenue du Colonel Roche, B.P. 4346, F-31028, Toulouse Cedex 4, France
}

Received: 15 February 2005 - Revised: 12 July 2005 - Accepted: 22 July 2005 - Published: 14 October 2005

\begin{abstract}
On the 25th January 2002 between 10:00 and 12:00 UT, the four Cluster spacecraft passed through the northern high-latitude cusp, the dayside magnetosphere and into the magnetosheath in a linear formation. In the magnetosphere the PEACE electron spectrometers on the four spacecraft all observed a series of transient bursts of magnetosheath-like plasma, but without bipolar magnetic signatures in the magnetopause normal component as might be expected if the plasma had been injected by transient reconnection (flux transfer events - FTEs). Reordering the data using the magnetopause transition parameter reveals that these plasma observations, the related variations in the magnetic field and the balance of magnetic and thermal gas pressures are consistent with transient entries into a stable highlatitude boundary layer structure. However, once some of the spacecraft entered the magnetosheath, FTE signatures were observed outside the magnetopause at the same time as some of the boundary layer entries occurred at the other spacecraft inside. Thus, (a) the lack of a bipolar $B_{N}$ signature is inconsistent with the traditional picture of a magnetospheric FTE, and (b) the cause of the observed entry of the spacecraft into the boundary layer (pressure pulse or passing magnetosheath FTE) can only be determined by spacecraft observations in the magnetosheath.
\end{abstract}

Keywords. Magnetospheric physics (Magnetopause, cusp and bondary layers; Solar wind- magnetosphere interactions; Magnetosheath)

\section{Introduction}

Russell and Elphic $(1978,1979)$ studied dayside low-latitude magnetopause crossings in magnetometer data using bound-

Correspondence to: R. C. Fear

(rcf@mssl.ucl.ac.uk) ary normal coordinates, defined such that the unit vector $\hat{N}$ was the outward pointing local magnetopause normal vector (deduced by minimum variance analysis, taking the vector product of the magnetosheath and magnetospheric fields, or from a model), $\hat{\boldsymbol{L}}$ lay parallel to the unperturbed magnetospheric field (i.e. points approximately northwards) and $\hat{M}$ completed the right-handed set $(\hat{\boldsymbol{L}}-\hat{\boldsymbol{M}}-\hat{\boldsymbol{N}})$, directed dawnwards. This coordinate system revealed examples of a signature consisting of a bipolar variation in the $\hat{N}$ component of the magnetic field, with simultaneous variations of the components in the $\hat{\boldsymbol{L}}$ and $\hat{\boldsymbol{M}}$ directions. In their dataset, the bipolar signature was always in the same sense (positive then negative), and the $B_{L}$ and $B_{M}$ variations were not consistent with ordinary crossings of the magnetopause. These signatures were observed both in the magnetosphere and the magnetosheath; Russell and Elphic named them "flux transfer events" or FTEs, interpreting them as signatures of impulsive reconnection (earlier observations of "flux erosion events" by Haerendel et al. (1978) were shown to be FTEs by Rijnbeek and Cowley (1984)).

The Russell and Elphic model was that of two open, kinked flux tubes formed by reconnection near the subsolar point, propagating tailward (one northward, one southward) in response to solar wind drag and changing form to reduce the magnetic tension $(\boldsymbol{j} \times \boldsymbol{B}$ force $)$. Neighbouring unreconnected field lines would drape over the flux tubes causing the bipolar $B_{N}$ signature and characteristic deviations in $B_{L}$ and $B_{M}$ as the FTE moved past the spacecraft (see also Farrugia et al., 1987a). Paschmann et al. (1982) also observed a bipolar $B_{N}$ signature when the reconnected flux tube was crossed; this was explained by a helicity which was added to the Russell and Elphic $(1978,1979)$ flux tube model by Sonnerup (1987). Field-aligned plasma populations originating from the opposite side of the magnetopause have been observed within FTEs (Daly et al., 1981; Paschmann et al., 1982) consistent with reconnection. The latter study noted 
the following "essential" features observed in all low-latitude FTEs: a southward component in the undisturbed magnetosheath magnetic field (negative $B_{L}$ ); a bipolar variation in $B_{N}$; an enhanced magnetic field strength $|\boldsymbol{B}|$ and an imbalance in the total pressure $\left(p_{\text {gas }}+B^{2} / 2 \mu_{0}\right)$ within both the flux tube and the draping region, countered by the tension in the draped magnetospheric/magnetosheath field lines. Simultaneous observations of the same FTEs on both sides of the magnetopause were first presented by Farrugia et al. (1987b). Other reconnection models of FTEs have been proposed that are consistent with these observations (multiple X-line: Lee and $\mathrm{Fu}, 1985$; bursty reconnection: Southwood et al., 1988 and Scholer, 1988).

Two alternative groups of models were also proposed to explain the observed bipolar signatures. The first hypothesis was that impulsive plasma penetration (Lemaire and Roth, 1978; Lemaire et al., 1979; Heikkila, 1982) could be a source mechanism for FTE signatures. These authors argued that impulsive penetration may occur when a plasma element in the solar wind has a larger momentum density compared with the background plasma. However, Smith and Curran (1990) showed that there is a poor correlation between FTE occurrence and the magnetopause penetration parameter derived by Lemaire et al. (1979), compared with the correlation between FTEs and magnetosheath $B_{L}$ (although they referred to the magnetosheath magnetic field as the interplanetary magnetic field [IMF]). This suggests that impulsive penetration is not the main cause of FTEs, although it continues to be discussed as a possible source (e.g. Lundin et al., 2003). Furthermore, Owen and Cowley (1991) disputed the mechanism proposed by Heikkila (1982).

The other group of models were proposed by Sibeck and colleagues (Sibeck et al., 1989; Sibeck, 1990, 1992; Sckopke, 1991). They suggested that magnetopause waves generate signatures similar to those observed by Russell and Elphic (1978) as spacecraft undergo successive crossings of near-magnetopause regions (magnetosphere, low-latitude boundary layer (LLBL), energetic particle layer, plasma depletion layer, magnetosheath). They argued that the magnetopause waves are caused by brief, impulsive, largeamplitude solar wind pressure pulses, and that the passing wave causes a bipolar normal signature. This model has been the cause of much debate (e.g. Lanzerotti, 1989; Elphic, 1990; Lockwood, 1991; Smith and Owen, 1992; Kawano et al., 1992; Elphic et al., 1994; Song et al., 1994, 1996; Sibeck and Newell, 1995, 1996; Sanny et al., 1996). In particular, Kawano et al. (1992) studied bipolar signature events near the low-latitude magnetopause, and concluded that long ( $B_{N}$ peak-to-peak time-scale $>90 \mathrm{~s}$ ) events showed no correlation with the interplanetary magnetic field (IMF) or $\mathrm{AE}$ index and occurred over a wide range of McIlwain L-shells. These were attributed to solar wind pressure variations. However short (time-scale $<90 \mathrm{~s}$ ) events tended to be observed near the magnetopause during periods of southward IMF and high AE index, and were ascribed to reconnection. Sanny et al. (1996) used similar criteria to identify bipolar "transient events" observed by the AMPTE CCE satellite across a wider range of radial distances from the Earth. The occurrence of these transient events was not correlated with the IMF orientation, and they were interpreted as signatures of solar wind/foreshock pressure pulses. However, six events were observed with a duration shorter than $90 \mathrm{~s}$; five of these were observed when the IMF was either steadily southward or fluctuated between northward and southward, consistent with the findings of Kawano et al. (1992).

Other studies, such as Hapgood and Lockwood (1995) and Lockwood and Hapgood (1998), have used the magnetopause transition parameter ( $\tau$, Bryant and Riggs, 1989; Hapgood and Bryant, 1990, 1992) to distinguish between different FTE models. $\tau$ is a proxy for the relative position of a spacecraft within boundary layers between the magnetosphere and the magnetosheath. It is derived by fitting a curve to plasma temperature and density moments (usually electron data), projecting each data point onto the nearest point of the best-fit curve and measuring the distance along the curve to each projection. These values are then normalised to extreme values on the curve, with 0 equating to the coolest/densest part of the magnetosheath and 100 the hottest/rarest point observed in the magnetosphere. The behaviour of $\tau$ has been shown to be consistent with passage of the spacecraft across magnetic field lines which have been reconnected for different lengths of time by Lockwood and Hapgood (1997).

The four-spacecraft Cluster mission allows the first multipoint observations in three dimensions. Cluster observations of high-latitude FTEs have been reported by Bosqued et al. (2001), Owen et al. (2001), Vontrat-Reberac et al. (2003) and Thompson et al. (2004). Lockwood et al. (2001) presented a study of a series of transient entries into the LLBL observed by Cluster during an interval of predominantly northward IMF. These entries correlated well with IMF clock angle $\left(\arctan \left(B_{Y} / B_{Z}\right)\right)$ swings to near $90^{\circ}$, typically from less than $60^{\circ}$, and with ground-based observations of transient reconnection signatures. Their occurrence was consistent with sub-solar reconnection (i.e. between magnetosheath and closed magnetospheric magnetic field lines, which may occur away from the equatorial plane). Whilst the events occurring in the "exterior" boundary layer (the newly-opened, northward-pointing magnetic field lines at the magnetopause) exhibited a weak bipolar $B_{N}$ signature, those events occurring in the "interior" boundary layer (southwardpointing field lines on the edge of the interior magnetic cusp) did not have a bipolar $B_{N}$ signature at all. Lockwood argued that this was because the bipolar signature is caused (under the Southwood/Scholer bursty reconnection model) by a pressure imbalance. In the interior boundary layer events, the enhanced magnetic pressure inside the events was approximately cancelled by a decrease in the ion gas pressure, whereas there was a net pressure increase in the exterior boundary layer events.

So far, the reconnection/pressure pulse debate has largely been constrained to lower latitudes. In this paper, we extend it to higher latitudes by presenting an analysis of two events from the 25th January 2002. In both cases, spacecraft within the magnetosphere observed signatures consistent 
with moving deeper into the observed boundary layer structure; however in the second example some spacecraft were in the magnetosheath, and they observed traditional FTE signatures.

\section{Observations}

\subsection{Spacecraft location}

On the 25th January 2002 the four Cluster spacecraft made an outbound pass through the northern magnetosphere into the magnetosheath at $15 \mathrm{~h}$ MLT. Figure 1 shows the positions and relative separations of the spacecraft in GSE during the period of interest between 10:00 UT (denoted by circles) and 12:00 UT (denoted by crosses). A period of orbital manoeuvres was under way, so as the spacecraft crossed the magnetopause they were in a linear formation, rather than a tetrahedron. Cluster 3 led the formation, followed by Clusters 1 and 4 (which were relatively close together) and then Cluster 2.

\subsection{Instrumentation and data}

In this paper, spectra and moments from the Plasma Electron and Current Experiment (PEACE: Fazakerley et al., 2005 ${ }^{1}$; Johnstone et al., 1997) on the four spacecraft are shown, together with supporting data from the Flux Gate Magnetometer (FGM: Balogh et al., 2001), the Cluster Ion Spectrometer (CIS: Rème et al., 2001) and the Electric Field and Wave experiment (EFW: Gustafsson et al., 2001). IMF data are provided by the ACE MAG instrument (Smith et al., 1998), lagged by a delay time calculated from the solar wind velocity observed by the ACE SWEPAM instrument (McComas et al., 1998).

The PEACE instruments on all four spacecraft consist of two detectors: the High Energy Electron Analyser and the Low Energy Electron Analyser (HEEA and LEEA). Onboard temperature and density moments, calculated using on-board calibrations and not corrected for the spacecraft potential, were telemetered by all four spacecraft during the period of interest. These are used in this paper as they are available at spin resolution $(4 \mathrm{~s})$, rather than ground moments derived from 3D reduced energy/angular resolution distributions (3DR) which are not available at spin resolution on Clusters 1, 3 and 4 during this interval. The effect of the non-zero spacecraft potential is minimised by the use of onboard moments from HEEA only (which covers the energy range $30 \mathrm{eV}$ to $26 \mathrm{keV}$ ).

All proton velocities and pressures presented are derived from CIS-CODIF ground moments, which are available at spin resolution from Cluster 4, and lower time resolution from Clusters 1 and 3. A dead-time correction has been applied to the Cluster 1 and 4 moments to improve accuracy in the magnetosheath, however this correction could not be applied to the data from Cluster 3 due to degradation of one

\footnotetext{
${ }^{1}$ Manuscript in preparation.
}
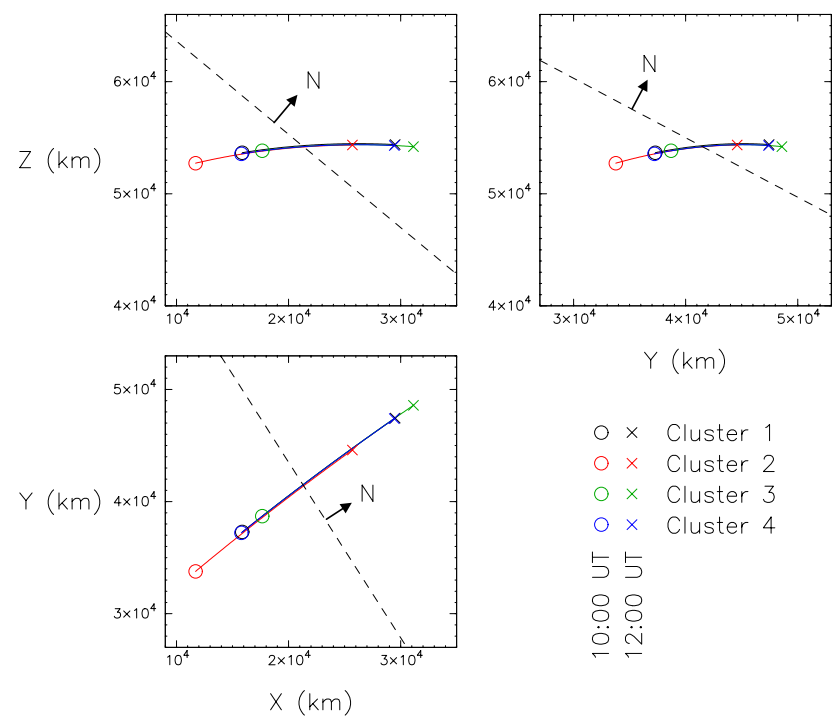

$0 \times$ Cluster 2

$0 \times$ Cluster 3

$0 \times$ Cluster 4

55

8

$\stackrel{\bigcirc}{\odot}$

Fig. 1. The Cluster orbit traces from 10:00 UT (marked by circles) to 12:00 UT (crosses) on the 25th January 2002, in the GSE $\mathrm{Z}-\mathrm{X}$ (top left), Z-Y (top right) and $\mathrm{Y}-\mathrm{X}$ (bottom left) planes. The traces are plotted in the standard Cluster colours shown in the key. As this interval occurred during a period of spacecraft manoeuvres, the spacecraft were oriented in a string formation as they crossed the magnetopause (between 10:41 and 11:12 UT), rather than a tetrahedron. The normal vector $\hat{N}$ derived in Sect. 2.5 has also been projected into the plane of each panel, along with the corresponding magnetopause plane.

quadrant of the sensor. Data are unavailable from CIS on Cluster 2. Magnetic field data from the FGM instrument are presented at both $5 \mathrm{~Hz}$ and spin resolution $(0.25 \mathrm{~Hz})$. The spacecraft potential measured by EFW is over-plotted on all spectrograms at spin resolution.

\subsection{Data overview}

Figure 2 shows two hours of Cluster and ACE data (10:0012:00 UT). The top four panels are spectrograms of the differential energy flux (DEF) measured by PEACE, averaged over all pitch angles. We shall refer to this as the omnidirectional DEF. The spacecraft potential is over-plotted on each panel as a red line; all electrons below the equivalent energy are caused by photoionisation of the spacecraft, and are not part of the natural plasma environment. The next four panels show the magnetic field observed by FGM (in standard Cluster colours: Cluster 1 in black, Cluster 2 in red, Cluster 3 in green and Cluster 4 in blue), and the ACE MAG instrument (magenta line, lagged by a calculated propagation time of $75 \mathrm{~min}$ and multiplied by a factor of four) in GSE coordinates. The Cluster FGM and ACE MAG data are shown at 4 and $16 \mathrm{~s}$ resolution respectively. The penultimate panel contains the total pressure observed by Clusters 1 and 4 , and the bottom panel shows $\tau$ for each spacecraft, which will be discussed in detail in Sect. 2.4. The magnetopause crossing of each satellite is indicated by a red vertical line (Cluster 3: 10:41 UT, Clusters 1 and 4: 10:46 UT, and Cluster 2: final 


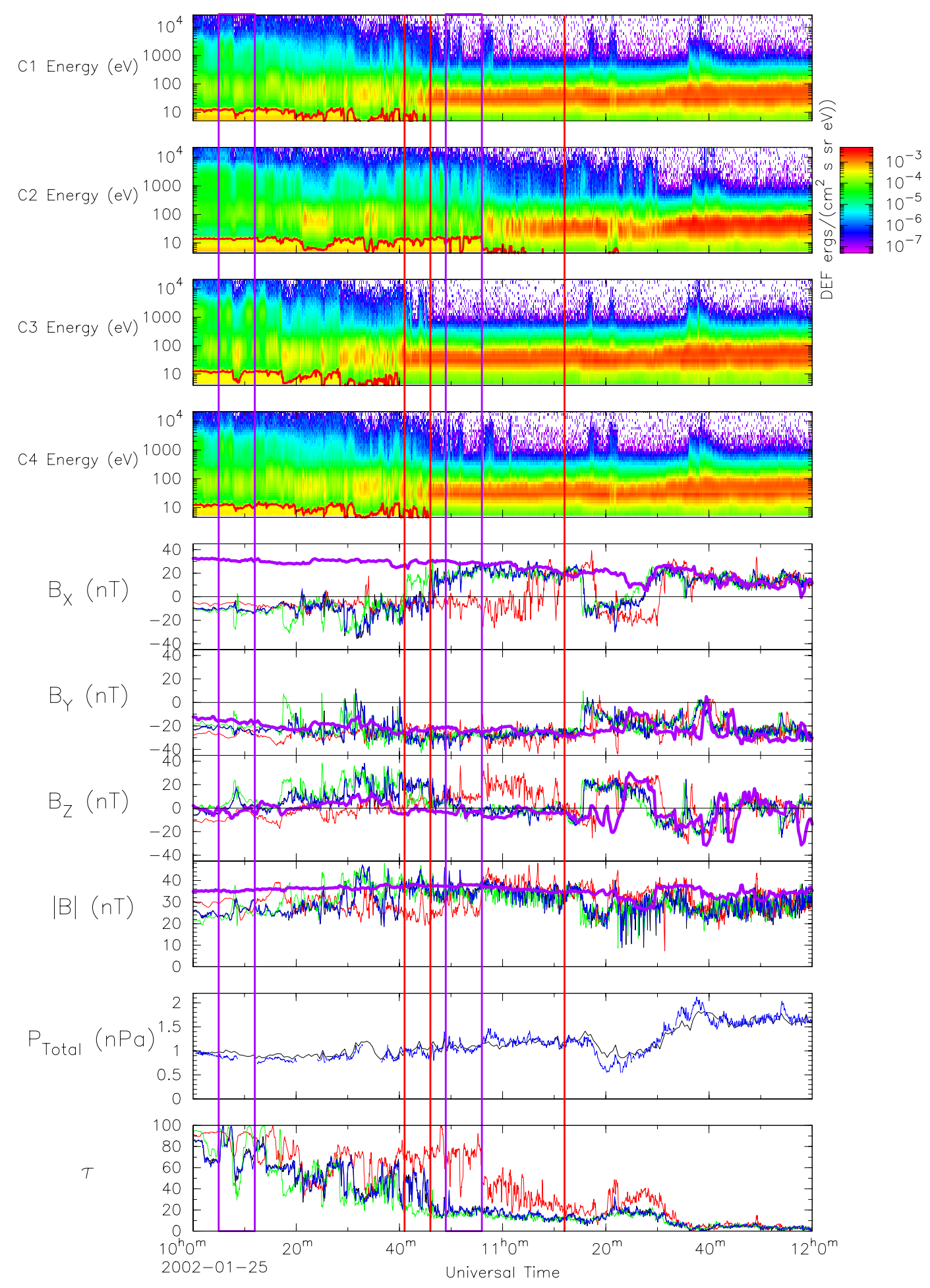

Fig. 2. An overview of the PEACE and FGM data and the interplanetary magnetic field (IMF). The top four panels are spectrograms of the omnidirectional electron differential energy flux observed by the PEACE instruments on Clusters 1, 2, 3 and 4 . The next four panels show the magnetic field observed by FGM on Clusters 1, 2, 3 and 4 in black, red, green and blue respectively in GSE coordinates. The magnetic field observed by ACE, lagged by $75 \mathrm{~min}$ and multiplied by a factor of 4, is over-plotted in magenta. The penultimate panel is the total pressure observed at Clusters 1 and 4 (calculated from the magnetic pressure and the thermal pressure derived from on-board CODIF moments corrected for dead-time effects). The bottom panel shows the magnetopause transition parameter calculated from the PEACE on-board moments. The magnetopause crossings made by Clusters 3,1 and 4, and 2 are shown by red lines at 10:41, 10:46 and 11:12 UT respectively, and the events analysed at 10:08 and 10:52 UT are indicated by magenta boxes. 
crossing at 11:12 UT), and two periods that will be the subject of detailed discussion in this paper are highlighted by magenta boxes (centred on 10:08 and 10:52 UT).

Between 10:00 and 12:00 UT the lagged interplanetary magnetic field (IMF) was generally stable and dominated in the GSE clock-angle ( $\mathrm{Y}-\mathrm{Z}$ ) plane by a negative $B_{Y}$ component, whilst $B_{Z}$ varied between slightly positive and slightly negative values. The clock angle was close to $-90^{\circ}$ until 11:20 UT (not shown). At the start of the interval shown, the PEACE instrument on each spacecraft observed a magnetospheric electron plasma distribution (hot, with relatively low differential energy fluxes) and FGM observed a relatively steady magnetic field of $\sim(-10,-20,0)_{G S E}$ nT. The near-zero component of the magnetospheric magnetic field in $Z_{G S E}$ indicates that the spacecraft were located near the lip of the magnetospheric cusp, where $B_{Z}$ changes from positive to negative on closed magnetospheric field lines. In the time leading up to the magnetopause crossings, intervals of plasma of magnetosheath energy $(\sim 100 \mathrm{eV})$ and differential energy fluxes of up to $10^{-3} \mathrm{ergs}\left(\mathrm{cm}^{2} \mathrm{~s} \mathrm{sreV}\right)^{-1}$ were observed from time to time, some of which corresponded to a rotation of the magnetic field which was enhanced in $-B_{X}$ and $+B_{Z}$, and diminished in $B_{Y}$. At the times indicated, the spacecraft crossed the magnetopause into the magnetosheath. Magnetopause crossings (defined as the final entry into the magnetosheath on each spacecraft) were determined by the appearance of an isotropic electron distribution at $\sim 100 \mathrm{eV}$ and a magnetic field rotation to $\sim(20,-20,0)_{G S E} \mathrm{nT}$. The Cluster 2 crossing is not as clear in the PEACE spectrogram, however the magnetic field data suggest that there were four transient magnetosheath entries, with the last occurring at 11:12 UT. The differential energy fluxes observed at $\sim 100 \mathrm{eV}$ in the magnetosheath were higher than the plasma at similar energies inside the magnetopause. A magnetic field reorientation, corresponding to a similar reorientation observed upstream by ACE, was observed in the magnetosheath between 11:15 and 11:30 UT. The total pressure remained relatively steady at $\sim 1 \mathrm{nPa}$ until the magnetosheath magnetic field reorientation occurred at 11:15 UT.

\subsection{Magnetopause transition parameter}

To aid discussion of this interval, the magnetopause transition parameter $(\tau)$ is introduced. It was calculated by fitting a curve to a $\log _{10}-\log _{10}$ scatter plot of electron density against perpendicular electron temperature using all data points between 10:00 and 12:00 UT for each spacecraft (Fig. 3). Detailed inter-calibration between electron moments from different spacecraft would have required the use of ground moments, which would have lowered the time resolution on Clusters 1, 3 and 4. Since all that is required to define a relative position of a spacecraft within the boundary layer is a consistent variation in the density and temperature, on-board moments from HEEA were used. As the data had not been inter-calibrated, best fit curves (4th order polynomials shown in Fig. 3) were calculated separately for each spacecraft. All data points were projected onto the

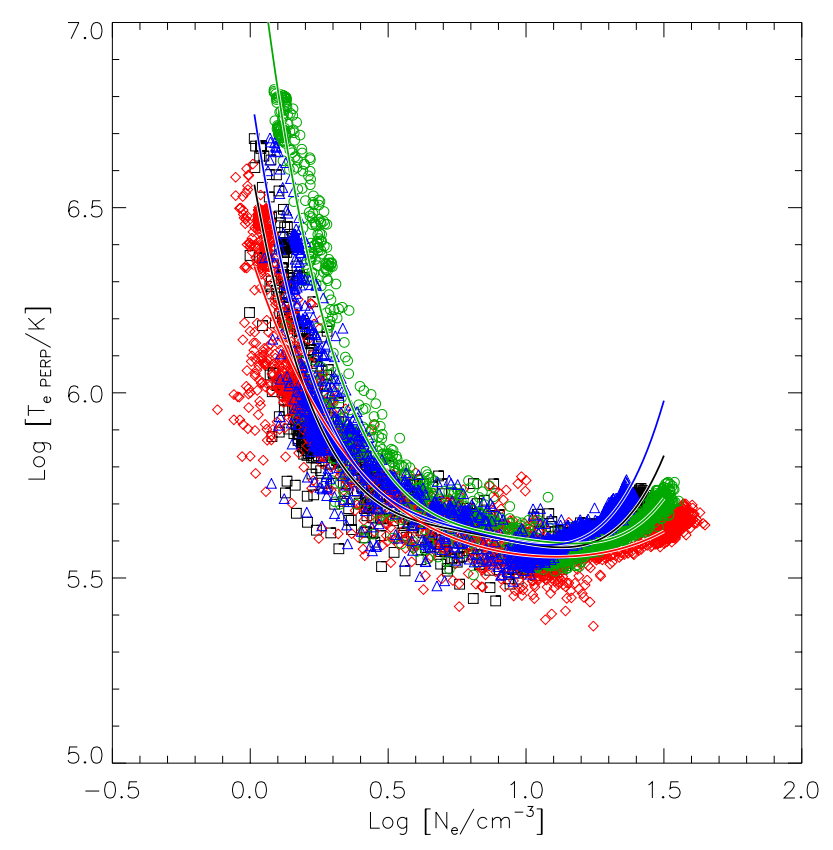

Fig. 3. A scatter plot of the perpendicular electron temperature against the electron density derived from PEACE on-board moments calculated by the HEEA sensor. A fourth order polynomial curve was fitted to the points from each spacecraft (shown). Each data point was projected onto the curve corresponding to the same spacecraft, and the distance along the curve to each projected point was converted to the transition parameter by normalising to extreme values.

nearest point of the corresponding curve. Extreme projected points were defined as 0 (in the magnetosheath) and 100 (in the magnetosphere) and the distance of each projected point along the curve, normalised to the extrema, was defined as $\tau$. The resulting transition parameter values for each spacecraft are plotted in the bottom panel of Fig. 2. The general trend in $\tau$ was a decrease until each spacecraft crossed the magnetopause, after which it stayed low. A brief enhancement of $\tau$ within the magnetosheath coincided with the magnetic field reorientation observed between 11:15 and 11:30 UT, as a region of solar wind with lower density arrived. After 11:30 UT, a region of solar wind at higher pressure arrived, which was associated with lower values of $\tau$.

Figure 4 shows spectrograms of the PEACE HEEA and LEEA data from the first and last spacecraft to cross the magnetopause (Cluster 3 and Cluster 2, which crossed the magnetopause thirty minutes apart) in the antiparallel, perpendicular and parallel pitch angle bins ordered by transition parameter rather than time. The data have been rebinned to pitch angles on the ground. The mean spacecraft potential is superposed as a red line. The general similarity of the two datasets in this figure demonstrates the persistence of a stable boundary structure for at least $30 \mathrm{~min}$ in the region of interest, although data from short-lived events can also be identified within this plot. Although the variations in this structure are generally gradual, four general regions can be distinguished. 


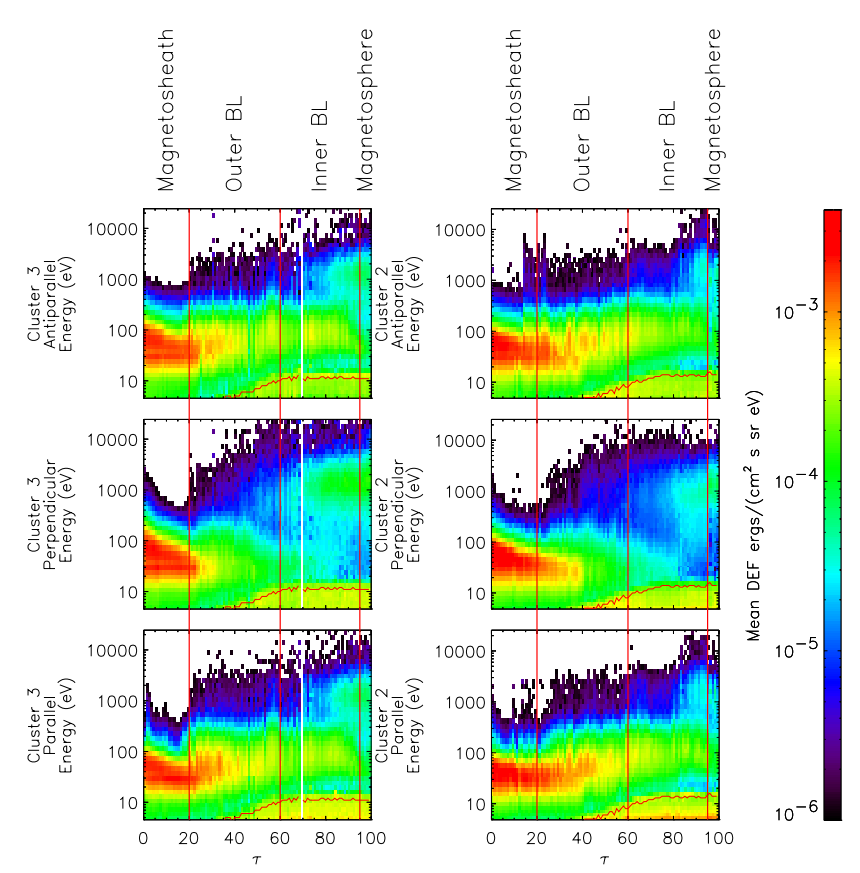

Fig. 4. Electron spectrograms from the first (Cluster 3, left-hand column) and last (Cluster 2, right-hand column) spacecraft to cross the magnetopause, reordered by transition parameter. Although the transition parameter values were derived from on-board moments from the HEEA sensors, both HEEA and LEEA data are shown in each panel. The top, middle and bottom rows show electron fluxes antiparallel, perpendicular and parallel to the magnetic field respectively. A stable boundary layer structure exists since there is little change between the structure observed at Clusters 3 and 2; similar structure is also observed by Clusters 1 and 4 . The regions identified in Sect. 2.4 (magnetosphere, inner and outer boundary layers and magnetosheath) are labelled, separated by red vertical lines.

The first region, in the range $95<\tau<100$, was the magnetospheric dayside plasma-sheet (seen most clearly on Cluster 3). Here there was a relatively low DEF of order $10^{-5} \mathrm{ergs}\left(\mathrm{cm}^{2} \mathrm{~s} \mathrm{sreV}\right)^{-1}$ at energies just above the spacecraft potential, and $\sim 10^{-4}$ ergs $\left(\mathrm{cm}^{2} \mathrm{~s} \mathrm{sr} \mathrm{eV}^{-1}\right.$ just above $1 \mathrm{keV}$ (but strongest perpendicular to the magnetic field), which is consistent with a trapped electron population.

Between $60<\tau<95$ the second region was observed, which we refer to as the inner boundary layer. At lower values of $\tau$ within this layer, a low energy $(10-100 \mathrm{eV})$ bidirectional field-aligned population of higher DEF replaced the $1 \mathrm{keV}$ population. The DEF increased, and the anisotropy decreased, with decreasing $\tau$. The trapped $\left(90^{\circ}\right) 1 \mathrm{keV}$ population disappeared between $\tau$ values of 70 and 80 .

A lower energy perpendicular population similar to that in the field-aligned directions appeared in the range $20<\tau<60$. The mean spacecraft potential also decreased in this region as $\tau$ decreased, consistent with an increase in plasma density towards magnetosheath values. The lack of magnetospheric electrons suggests that this plasma was on open magnetic field lines; we call this the outer boundary layer.
For $\tau<20$ the low-energy DEF reached its peak of $\sim 10^{-3} \mathrm{ergs}\left(\mathrm{cm}^{2} \mathrm{~s} \mathrm{sreV}\right)^{-1}$ and the distribution became isotropic. This was the fourth region: the magnetosheath. These regions were identified according to the value of $\tau$, which is indicative of the time elapsed since the magnetic field line was reconnected. The terms "inner" and "outer" boundary layer are used in a completely different sense from the interior and exterior layers of Lockwood et al. (2001) which was based on $B_{Z}$, and hence position relative to the cusp in a GSE $X-Y$ plane. Due to motion of the magnetopause as the spacecraft approach and pass the mean position of the boundary layer, the layer was encountered by each spacecraft intermittently at first and then steadily until the magnetosheath was entered (Fig. 2).

Figure 5 shows the variation of the magnetic field and CODIF proton parameters in GSE coordinates as a function of corresponding transition parameter. The top four panels show the variation with $\tau$ of the magnetic field on all four spacecraft. Data from the period of magnetosheath magnetic field reorientation (11:15 to 11:30 UT on Clusters 1, 3 and 4; 11:16 to 11:32 UT on Cluster 2) have not been plotted in these panels. Whilst a magnetospheric magnetic field orientation was maintained to values as low as $\tau=60$, in the region $20<\tau<60$ (the outer boundary layer) a magnetic field orientation was observed which differed from both the magnetosphere and the magnetosheath. There was a wider spread of values in this region, but the magnitude of the magnetic field was generally stronger than either side, the $B_{X}$ and $B_{Z}$ components were enhanced, and $B_{Y}$ decreased. At $\tau=20$ there was a clear reversal in $B_{X}$ and $B_{Z}$, and at smaller values of $\tau$ there was a consistently Sunward, duskward and generally southward magnetic field orientation.

The next four panels of Fig. 5 show the dead-time corrected CODIF ground moment velocities from Clusters 1 and 4 (which were located relatively close together). The moments from Cluster 3 are not shown, as without the dead-time correction they are not believed to be accurate in the magnetosheath; therefore it is hard to show long-lasting stability in the trends of the proton data. In most of the inner boundary layer $(60<\tau<95)$, there was little deviation from the low bulk velocities observed in the magnetosphere. In the outer boundary layer ion velocities were generally either similar to those observed in the magnetosheath or to those in the magnetosphere. However there were some enhancements, predominantly in $-V_{X}$, which increased the magnitude of the ion velocity to greater than that of the magnetosheath flow.

The next three panels show the thermal pressure calculated from the dead-time corrected CODIF density and temperature ground moments, the magnetic pressure and the sum of these two pressures. There was a decrease in the gas pressure and an increase in the magnetic pressure in the outer boundary layer compared with the inner boundary layer and the magnetosphere. Although temporal variations caused a slight spread in values of total pressure $( \pm 0.2 \mathrm{nPa}$ above $\tau=40$; $\pm 0.5 \mathrm{nPa}$ in the region $18<\tau<40$ ), the mean value of the total pressure remained close to $1 \mathrm{nPa}$ down to $\tau=18$. Pressure 


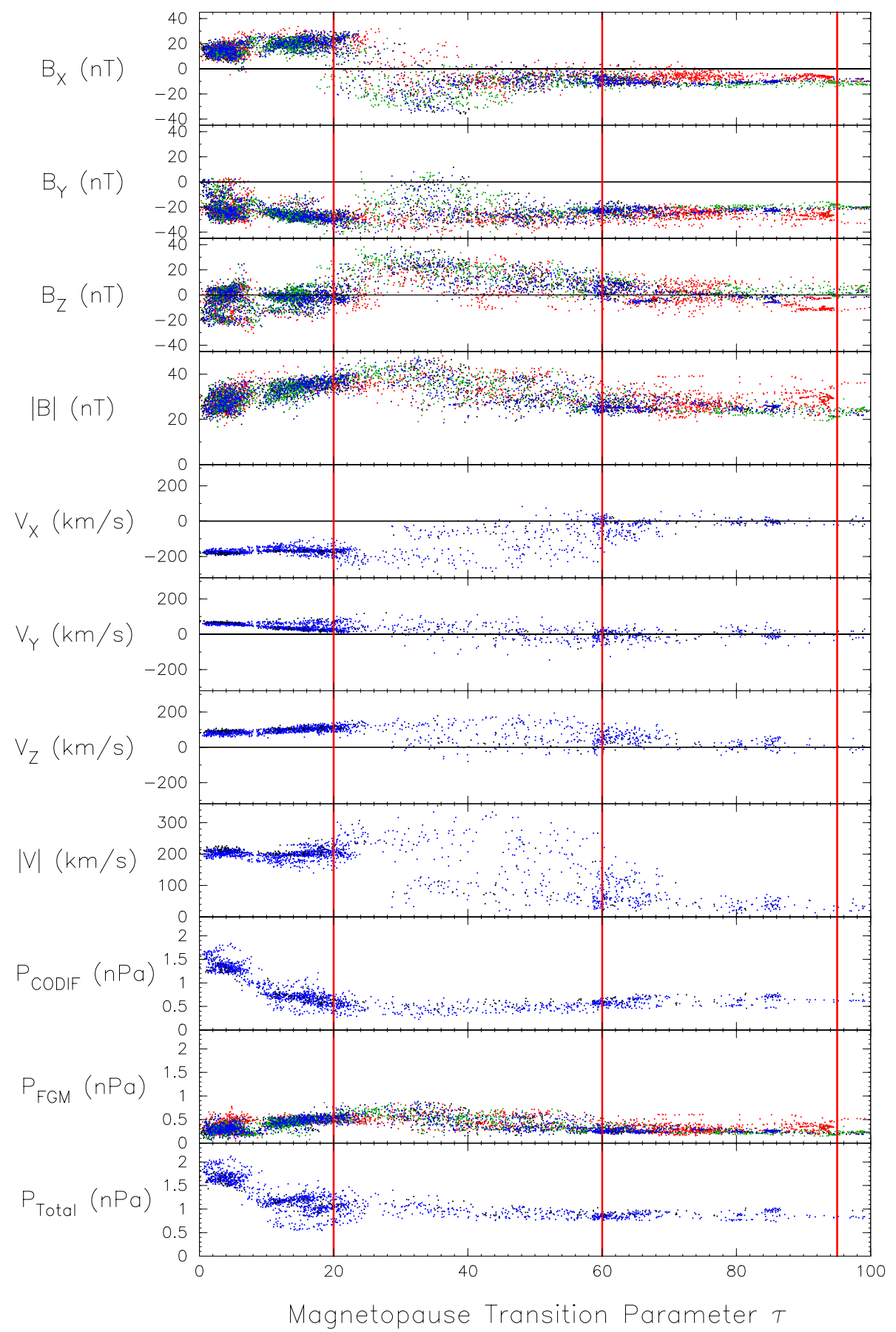

Fig. 5. The magnetic field, proton velocity and gas, magnetic and total pressure reordered by transition parameter. The proton velocities and pressure are derived from CODIF ground moments which have undergone a dead-time correction to improve their accuracy in the magnetosheath. A period of magnetosheath magnetic field reorientation (11:15 to 11:30 UT on Clusters 1, 3 and 4; 11:16 to 11:32 UT on Cluster 2) has been removed from the top four panels. The boundaries between the magnetosheath, outer and inner boundary layers and magnetosphere are indicated by vertical lines.

balance was thus conserved both between the magnetosphere and boundary layers, and the boundary layers and the magnetosheath. After the spacecraft entered the magnetosheath, the total pressure varied more in time (penultimate panel of Fig. 2). This caused a larger spread of values and a general increase in $P_{\text {Total }}$ corresponding to $\tau<18$.

\subsection{Boundary normal coordinates}

In order to examine the two events highlighted in Fig. 2, a boundary normal coordinate system was established. The linear formation of the spacecraft precluded using a multispacecraft timing analysis as a means of establishing the 
normal vector $\hat{N}$. Therefore $\hat{N}=(0.592,0.378,0.712)_{G S E}$ was determined by minimum variance analysis (MVA) performed using high resolution FGM data across the field rotation between the outer boundary layer and the magnetosheath. Current magnetopause models do not account for any effect of the cusp on the magnetopause shape, but $\hat{N}$ compares with a Roelof and Sibeck (1993) model normal of $(0.664,0.437,0.607)_{G S E}$. The angle between these two normal vectors is $8^{\circ}$. A variety of intervals were used for MVA on all four spacecraft; the largest intermediate/minimum eigenvalue ratio achieved was 4.3 , using Cluster 2 data from 10:50 to 11:50 UT. Whilst this ratio is low, and the interval is wide, the MVA frame which was derived did succeed in producing a minimum component of the magnetosheath magnetic field that is close to zero. This is consistent with magnetic field draping over the magnetopause. $\hat{\boldsymbol{L}}=(-0.715,-0.161,0.680)_{G S E}$ was determined by projecting the Earth's magnetic dipole onto the plane defined by $\hat{\boldsymbol{N}}$, and $\hat{\boldsymbol{M}}=(0.372,-0.912,0.175)_{G S E}$ was constructed from the vector product of $\hat{N}$ and $\hat{\boldsymbol{L}}$.

The magnetic field and proton velocity variations are plotted in boundary normal coordinates as a function of $\tau$ in Fig. 6, in the same format as Fig. 5. As in Fig. 5, the period of magnetosheath magnetic field reorientation (between 11:15 and 11:30 UT on Clusters 1, 3 and 4; 11:16 to 11:32 UT on Cluster 2) has not been plotted in the magnetic field panels. Since the boundary normal coordinate frame was derived at the entry into the magnetosheath, which does not equate to the exit from the magnetosphere-proper, the magnetospheric magnetic field $(\tau \sim 100)$ was not entirely in $B_{L}$; there was also a positive $B_{M}$ component, and $B_{N}$ was negative as the proximity to the cusp meant that the magnetospheric magnetic field lines observed earlier in the interval had a component away from the magnetopause plane derived from the later crossings. As the spacecraft passed through the outer boundary layer, $B_{L}$ was enhanced, $B_{M}$ increased slightly but sometimes became negative, and $B_{N}$ decreased (sometimes becoming positive). On entry into the magnetosheath, $B_{L}$ reversed direction and became negative, $B_{M}$ was positive and $B_{N}$ decreased back to zero. As is expected, the magnetosheath flow was almost entirely in the magnetopause plane (positive $V_{L}$ and negative $V_{M}$ ). As noted in the discussion of Fig. 5 , the boundary layer flow velocity vectors were generally either similar to the flow observed in the magnetosheath or similar to the negligible flow in the magnetosphere. However, there were some enhancements in $V_{L}$ and $V_{M}$ and there were a significant number of positive $V_{M}$ values in the range $\tau>30$.

\subsection{Case studies}

\subsubsection{0:08 UT Boundary layer entry}

The first event we shall consider occurred at 10:08 UT. Plasma and magnetic field data for the period 10:0010:15 UT are shown in Fig. 7. Electron spectra from Cluster 3 in the directions antiparallel, perpendicular and parallel to the magnetic field are plotted in the top three panels. The data in these plots have been rebinned to pitch angles on the ground. Rebinning improves the reliability of the binning, since on-board binning uses on-board calibrations and bases the pitch angle on a single magnetic field value measured during the spin beforehand. If the magnetic field changes during a spin, the pitch angle selection may miss some pitch angles, usually near the magnetic field direction, as is seen near 10:08 UT. These spectrograms are followed by equivalent spectrograms for Cluster 4; the magnetic field did not change rapidly enough to cause problems for on-board pitch angle selection, therefore on-board binning has been used for this spacecraft. The spacecraft potential is again superposed onto each spectrogram.

The next four panels display the CODIF proton velocity moments in boundary normal coordinates. These panels are followed by the high resolution magnetic field data in boundary normal coordinates, the thermal gas pressure derived from CODIF ground moments, the magnetic and total pressures and the transition parameter. Moments from Clusters 1 and 4 are dead-time corrected.

Between 10:00 and 10:02 UT, all four spacecraft were near the magnetosphere/inner boundary layer transition. In this interval the magnetic field maintained a steady value of $\sim(10,10,-20)_{L M N} \mathrm{nT}$, the proton velocity was low and the transition parameter was approximately 90 . Between 10:02 and 10:05 UT, the transition parameter on Clusters 1,3 and 4 dropped to 70 . A higher DEF, of order $5 \times 10^{-4} \mathrm{ergs}\left(\mathrm{cm}^{2} \mathrm{~s} \mathrm{sr} \mathrm{eV}\right)^{-1}$, of field-aligned plasma below $100 \mathrm{eV}$ is evident in the spectrograms, and there was a dropout of $1 \mathrm{keV}$ plasma in the field-aligned directions. Similar spectra and values of $\tau$ were observed by Clusters 1,3 and 4 at 10:12 UT and after 10:14 UT. These signatures are consistent with the behaviour in Figs. 4, 5 and 6; at these values of $\tau$, the spacecraft were well inside the inner boundary layer: no variation was observed in the magnetic field or bulk velocities, but bidirectional field-aligned plasma was observed.

At 10:08 UT, a deeper transient entry into the boundary layer structure was observed. $\tau$ dropped to 30 on Cluster 3 and 40 on Clusters 1 and 4 . Cluster 3 observed an even higher DEF burst of low energy plasma in the field-aligned directions $\left(\sim 4 \times 10^{-3} \operatorname{ergs}\left(\mathrm{cm}^{2} \mathrm{~s} \mathrm{sreV}\right)^{-1}\right)$. There was also an enhancement of plasma at this energy in the perpendicular direction, but only to a DEF of $10^{-4} \operatorname{ergs}\left(\mathrm{cm}^{2} \mathrm{~s} \mathrm{sreV}\right)^{-1}$, and a drop-out in electrons in all directions at $\sim 1 \mathrm{keV}$. Cluster 4 observed a DEF of $\sim 5 \times 10^{-4} \operatorname{ergs}\left(\mathrm{cm}^{2} \mathrm{~s} \mathrm{sreV}\right)^{-1}$ in the field-aligned directions, with little enhancement in the perpendicular direction. At the same time, Clusters 1 and 4 observed an increase in $B_{L}, B_{M}$ and $|\boldsymbol{B}|$, whilst $B_{N}$ decreased to nearly zero. The Cluster 3 magnetic field followed this behaviour at edges of the signatures (before 10:07.45 and after 10:08.30 UT), but between these times $B_{M}$ turned negative. There was an enhancement in the plasma velocity on these three spacecraft, which largely consisted of an increase in $V_{M}$, but within this enhancement $V_{M}$ observed by Cluster 3 also reversed direction. There was also a 


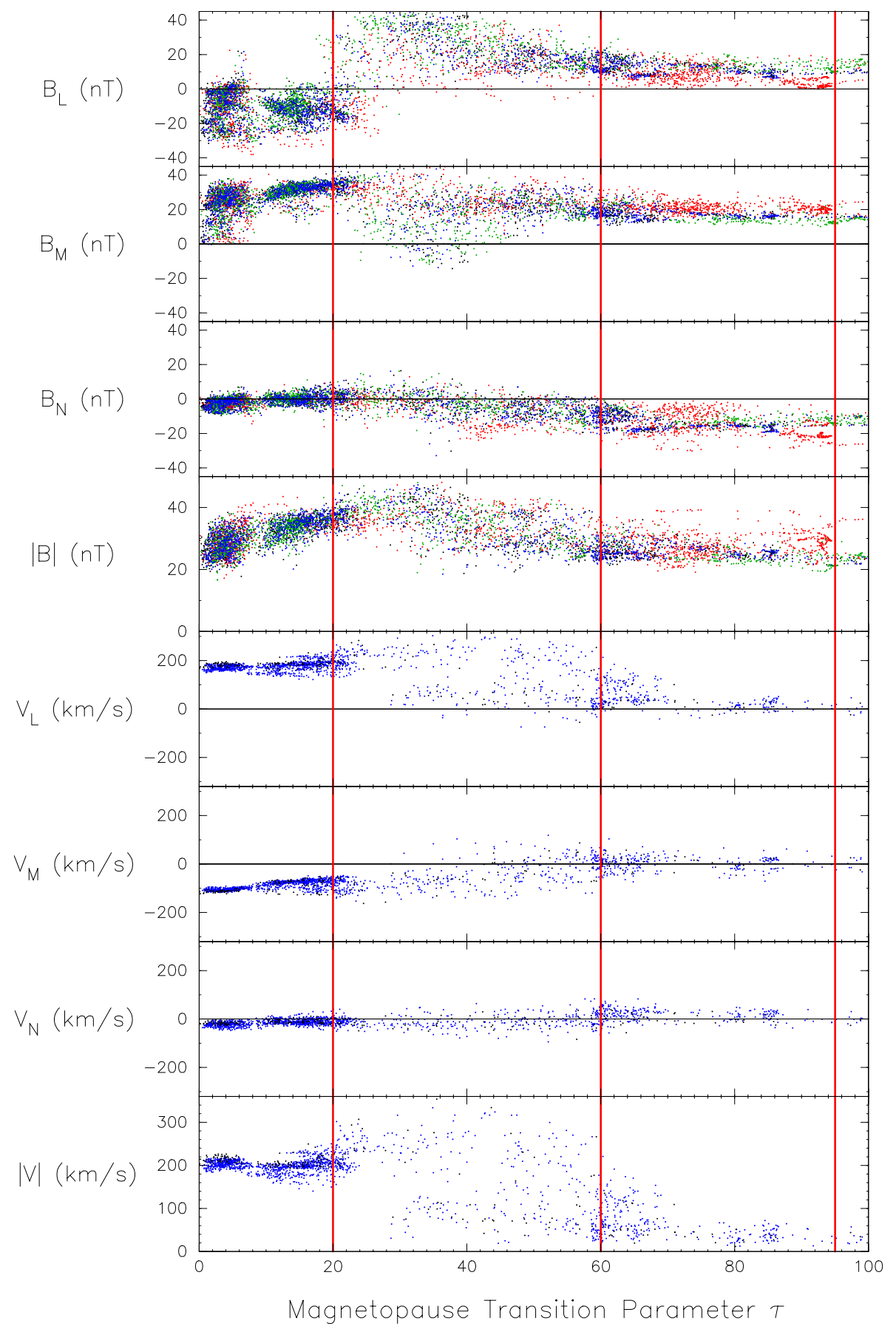

Fig. 6. The magnetic field and proton velocity data shown in Fig. 5, rotated into boundary normal coordinates.

brief $V_{L}$ enhancement on Cluster 3. The proton gas pressure on all three spacecraft decreased, but this was approximately cancelled by an enhancement of the magnetic pressure. The signature observed by Cluster 3 was preceded by a $V_{N}$ flow of $\sim-80 \mathrm{~km} / \mathrm{s}$ and followed by a positive $V_{N}$ flow of $\sim 60 \mathrm{~km} / \mathrm{s}$; this bipolar flow pattern had a duration of 5 min.

Cluster 2 also observed a small increase in DEF below $100 \mathrm{eV}$ at 10:08 UT (seen in Fig. 2), and a drop in $\tau$. However, these occurred slightly before those observed at Clus- ter 3. Since Cluster 3 observed these signatures before Clusters 1 and 4 and the variation of $\tau$ on Cluster 2 between 10:00 and 10:15 UT is not closely related to the variation observed by the other spacecraft, we believe this to be a separate boundary layer entry (Cluster 2 was separated from Cluster 1 by $4400 \mathrm{~km}$ in $\hat{N}$, and by $3300 \mathrm{~km}$ tangential to the magnetopause plane).

The $B_{L}, B_{M}$ and magnetic pressure enhancements, along with the decrease in $B_{N}$ and the gas pressure observed on all three spacecraft are consistent with the trends illustrated in 


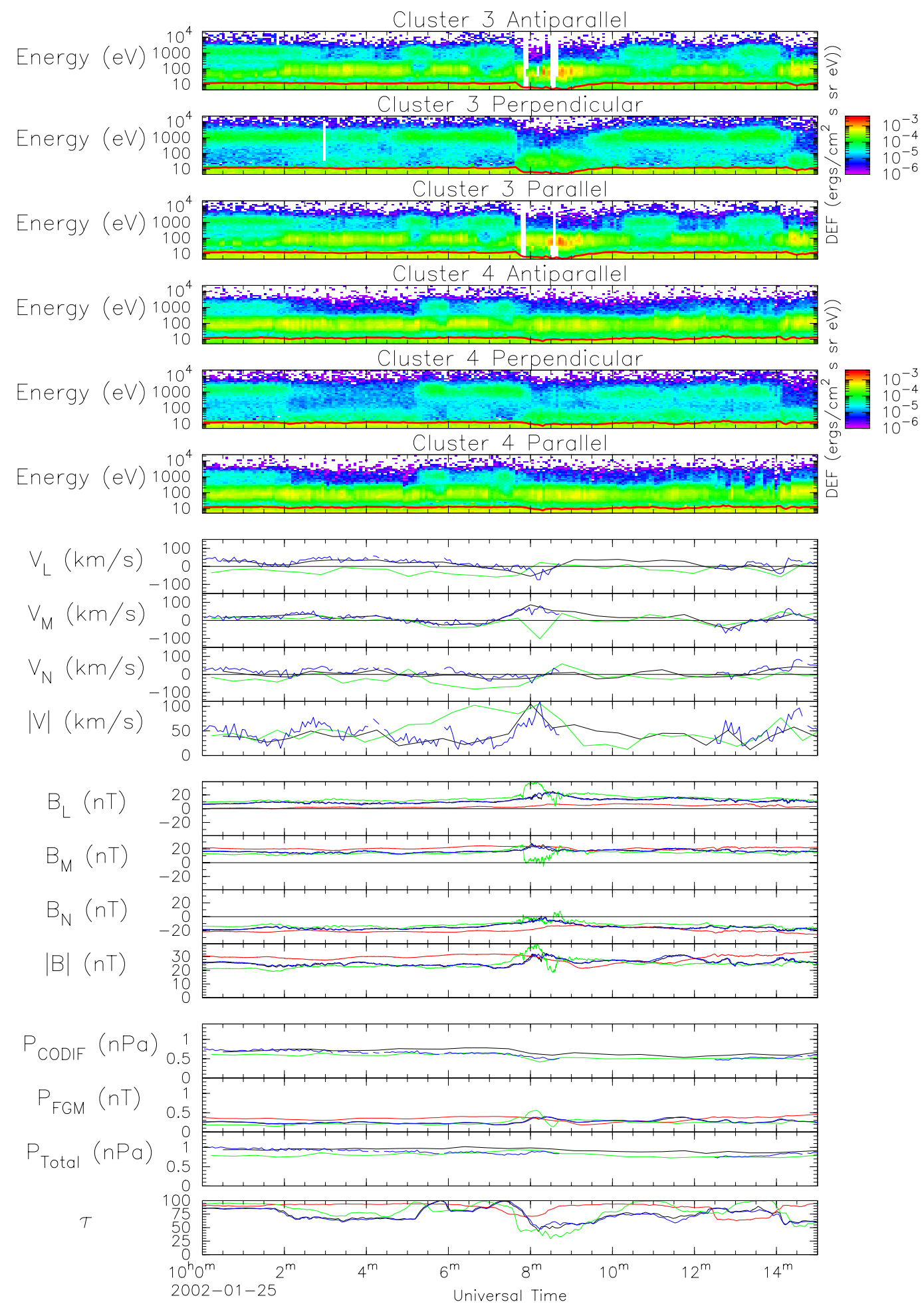

Fig. 7. Plasma and magnetic field data from the 10:08 UT event. The top six panels show electron spectrograms from Cluster 3 (closest to the magnetopause) and Cluster 4 antiparallel, perpendicular and parallel to the magnetic field. The Cluster 4 spectrograms show data resulting from on-board binning of measured data into pitch angle bins, but the Cluster 3 data have been rebinned on the ground, which results in some data gaps. The next four panels show the proton ground moment velocities in boundary normal coordinates for Clusters 1 and 4 (corrected for dead-time effects) and Cluster 3. They are followed by the high resolution magnetic field observed on each spacecraft (also in boundary normal coordinates), and the gas, magnetic and total pressures. The final panel shows the transition parameter calculated for each spacecraft. 
Figs. 5 and 6 associated with the observed decrease to $\tau \approx 40$. Although at this value of $\tau$ the mean value of $V_{L}$ increased and $V_{M}$ became negative, there was a considerable spread and the observed values on Clusters 1 and 4 at 10:08 UT did not lie significantly outside this distribution. The $B_{M}$ and $V_{M}$ reversals observed by Cluster 3 are also consistent with the slightly deeper penetration into the outer boundary layer made by Cluster 3 , due to its position closer to the magnetopause than the other spacecraft.

\subsubsection{0:52 UT Flux transfer event}

After 10:30 UT the lagged IMF was generally southwards, although still dominated in the clock-angle plane by $B_{Y}$ (Fig. 2). Following their respective magnetopause crossings, all four spacecraft observed traditional magnetosheath FTE signatures (bipolar $B_{N}$ signatures and an enhancement in the magnetic field strength; some exhibited a heating of magnetosheath electron plasma, proton velocity enhancements and an increase in the transition parameter). Four such FTEs, identified by their characteristic bipolar $B_{N}$ variations, are shown in Fig. 8, at 10:48.45, 10:49.40, 10:50.20 and 10:51.50 UT.

Figure 8 , showing the period from 10:48 to 10:56 UT, adopts the same format as Fig. 7 except that spectrograms from Clusters 4 and 2 are shown. On-board binning is again used for Cluster 4 data since the magnetic field did not change rapidly enough to affect the on-board pitch angle selection, but Cluster 2 data have been rebinned to pitch angles on the ground. By this time, Clusters 1, 3 and 4 had crossed into the magnetosheath; the Cluster 3 CODIF moments are not shown since they are unreliable in the magnetosheath without the dead-time correction. These three spacecraft observed a cool, dense, isotropic electron plasma distribution typical of the magnetosheath, corresponding to a low transition parameter. The plasma flow direction was in $+V_{L}$ and $-V_{M}$, and the magnetosheath magnetic field was predominantly along $B_{M}$. Just before 10:52 UT, Clusters 1 and $4 \mathrm{ob-}$ served a "standard" polarity (outward then Earthward) bipolar $B_{N}$ FTE signature in the terminology of Rijnbeek et al. (1984), which is shown in more detail in Fig. 9. An enhancement in $B_{L}$, a decrease in $B_{M}$ and a small velocity enhancement were also observed. There was a small increase in the total pressure observed by these spacecraft due to an increase in the magnetic pressure, and the PEACE instruments observed accelerated magnetosheath electrons in the direction parallel to the magnetic field (Cluster 1 spectrogram not shown).

By this time Cluster 3 (the leading spacecraft in the formation - see Fig. 1) was too far from the magnetopause to observe a change in the electron spectra, but a small amount of bipolar $B_{N}$ draping was observed. On the other side of the magnetopause, Cluster 2 observed similar, although shorter lived, signatures to those which had been observed by Cluster 3 at 10:08 UT (see Fig. 9). As the transition parameter dropped from around 80 to approximately 40, a burst of low energy field-aligned plasma was observed with a DEF of or- der $10^{-3}$ ergs $\left(\mathrm{cm}^{2} \mathrm{~s} \mathrm{sreV}\right)^{-1}$. The DEF of plasma in the perpendicular direction also rose to $\sim 10^{-4} \mathrm{ergs}\left(\mathrm{cm}^{2} \mathrm{~s} \mathrm{sreV}\right)^{-1}$. The magnetic field strength also increased, but this increase consisted of an enhancement in $B_{L}$, a decrease in $B_{M}$ and a unipolar positive excursion in $B_{N}$.

\section{Discussion}

Using the transition parameter introduced by Hapgood and Bryant (1992), we have analysed the basic characteristics of the cusp/magnetopause boundary layers observed by Cluster on the 25th January 2002, when Cluster passed from within the magnetosphere near the rim of the cusp (i.e. where the magnetospheric magnetic field turns from positive to negative GSE $B_{Z}$ ) via a boundary layer to the magnetosheath. This analysis revealed an inner boundary layer with bidirectional low-energy plasma and a similar magnetic field orientation to the magnetosphere, and an outer layer with lower anisotropy and higher fluxes than in the inner boundary layer, and with a different magnetic field orientation from the magnetosphere and magnetosheath. Details of the boundary layer structure are expected to relate to the age of the reconnected field lines. Further work on this topic is planned, but the presence of trapped electrons $\left(90^{\circ}\right.$ pitch angle) in part of the inner boundary layer $(\tau>\sim 80)$ suggests that this region was on closed magnetic field lines or field lines from which not all magnetospheric electrons had had time to escape. The electron distribution in the inner boundary layer, and similarity of the inner boundary layer magnetic field to that of the magnetosphere-proper are consistent with being magnetically connected to the LLBL/cleft. The electron distribution of the outer boundary layer is consistent with the exterior cusp (heated electrons at a lower DEF than in the magnetosheath, without a trapped population). Furthermore, we suggest that the occurrence of plasma with bulk velocities greater than the magnetosheath (Figs. 5 and 6) implies that sub-solar reconnection was occurring. This is consistent with the negative IMF $B_{Z}$ excursions which were occurring at the same time (Fig. 2).

In this context, we examined an example event at 10:08 UT, where the Cluster spacecraft penetrated the boundary layers to three different depths: Cluster 3 entered deeper than Clusters 1 and 4 and observed a greater DEF enhancement in all directions (largest in the field-aligned directions). Cluster 4 (and Cluster 1) only observed a significant increase in the field-aligned directions. All three spacecraft observed a positive enhancement in $V_{M}, B_{L}$ and $B_{M}$ and a decrease in $B_{N}$ (which became positive on Cluster 3); in addition, Cluster 3 observed reversals in $V_{M}$ and $B_{M}$. Cluster 2 made a shallower entry into the inner boundary layer around this time, but since the variations in $\tau$ observed on this spacecraft do not relate closely to those observed by the other three it is believed that this was caused separately. Therefore the scale size of these events was smaller than the separation of Cluster 2 from Clusters 1 and $4(4400 \mathrm{~km}$ in $\hat{N}$, and $3300 \mathrm{~km}$ tangential to the magnetopause plane). The proton 


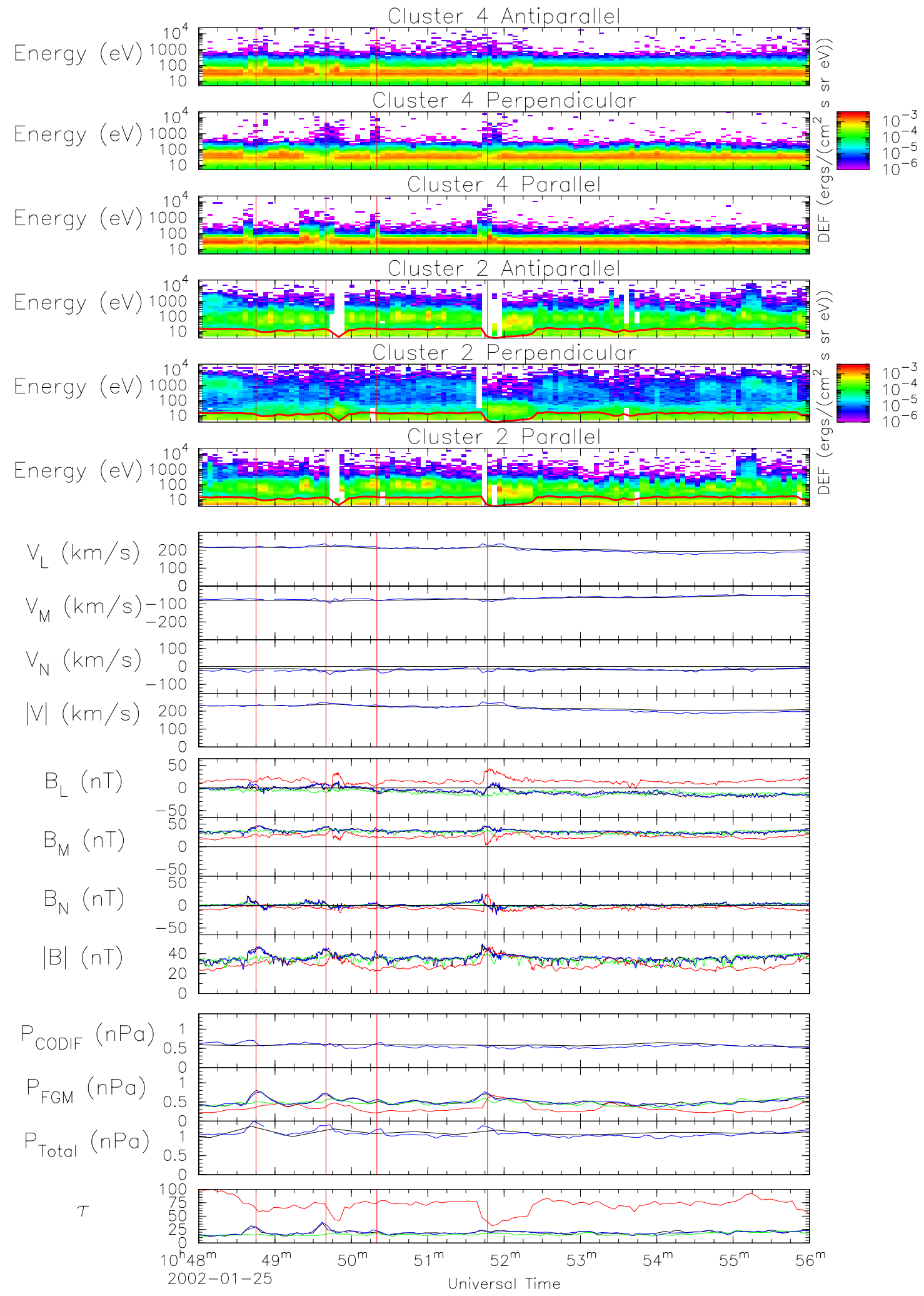

Fig. 8. Plasma and magnetic field data from the 10:52 UT event. This figure follows the same layout as Fig. 7, except that spectrograms for Clusters 4 and 2 are shown (Cluster 4 data use on-board pitch angle binning; Cluster 2 data have been rebinned on the ground). Cluster 3 moments are not shown as the lack of dead-time correction reduces their reliability in the magnetosheath. Four magnetosheath FTEs are identified by vertical red lines. 

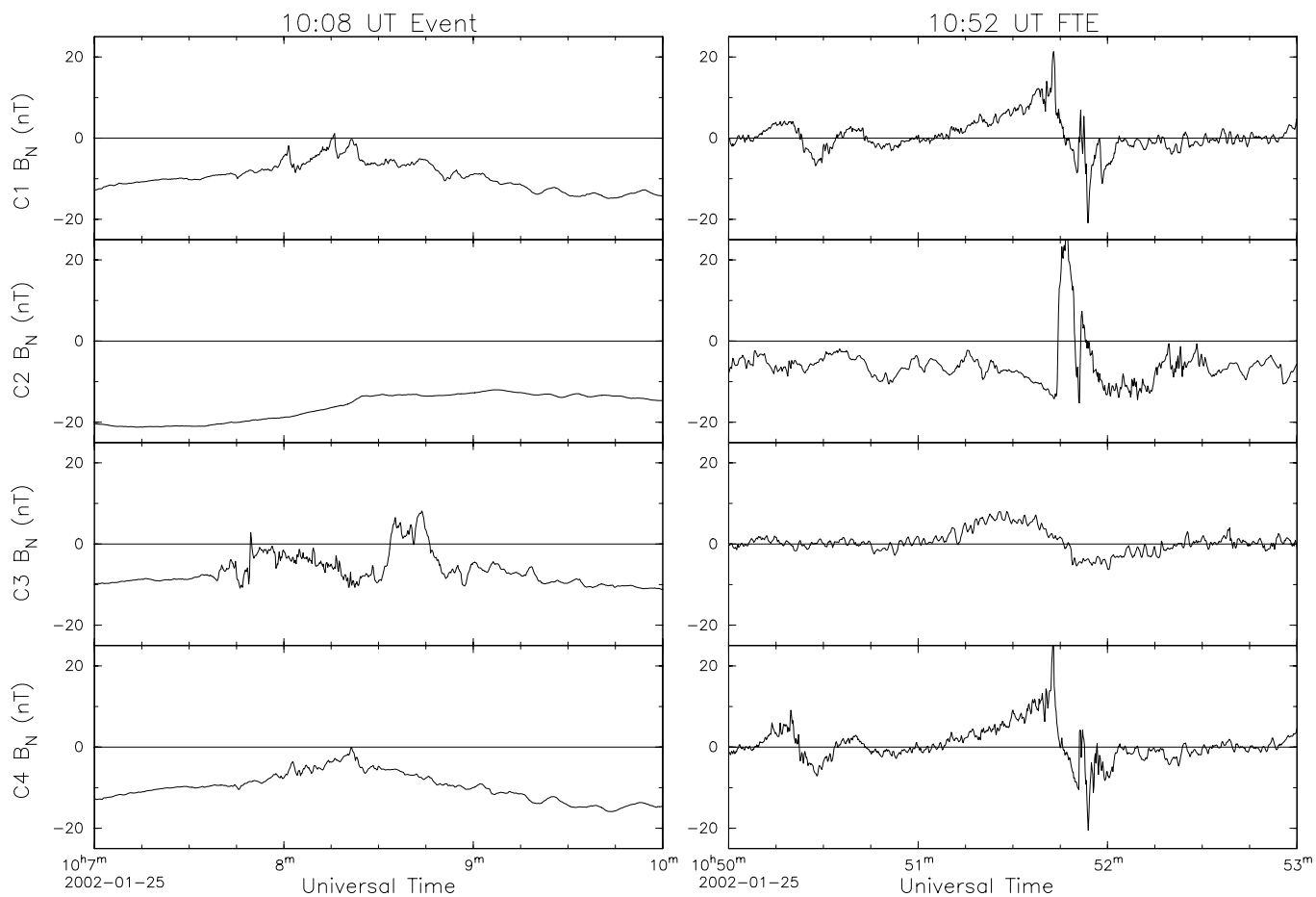

Fig. 9. The $B_{N}$ signatures observed by the four Cluster spacecraft at 10:08 and 10:52 UT.

velocity components normal to the magnetopause observed by Cluster 3 before/after the magnetic field signatures show that there was an inward/outward bulk motion of the plasma with a duration of $5 \mathrm{~min}$, but in the absence of observations in the magnetosheath and solar wind there is no conclusive evidence for whether this boundary layer entry was caused by a simple pressure pulse or if it had another cause, such as a passing FTE.

At 10:52 UT, the spacecraft in the magnetosheath (Clusters 1, 3 and 4) observed signatures which can be attributed to flux transfer events (bipolar $B_{N}$ signatures, field-aligned acceleration of magnetosheath electrons, and an increase in the magnetic pressure). Cluster 2 was already in the inner boundary layer, but unlike earlier simultaneous observations of FTEs either side of the low-latitude magnetopause (e.g. Farrugia et al., 1987b), no bipolar $B_{N}$ signature was observed. At the low-latitude magnetopause, there is usually a simple rotation directly between the magnetospheric and magnetosheath magnetic fields. In the 10:52 UT event, a range of characteristics were observed which were consistent with moving deeper into the temporally stable boundary layer structure as the FTEs passed by (sketched in Fig. 10). In fact, few bipolar $B_{N}$ signatures occurred in the magnetosphere or within the boundary layer during this interval; they were first observed just before the spacecraft crossed the magnetopause. One explanation for the observed signatures might be that the velocity of the FTE has a strong component antiparallel to the magnetosheath magnetic field, producing a clear standard-polarity bipolar signature through draping of the magnetic field lines, but only a weak component along the magnetic field directions observed by the spacecraft in the boundary layer/magnetosphere. However the best measure we have of the velocity of the FTE is the peak perpendicular velocity, observed in the corrected CODIF moments at 10:51.55 UT, which is $(239,-48,-15)_{L M N} \mathrm{~km} \mathrm{~s}^{-1}$ (not shown). The background magnetosheath and inner boundary layer magnetic fields, observed by Clusters 4 and 2 respectively at 10:51.20 $\mathrm{UT}$, are $(-7,35,3)_{L M N} \mathrm{nT}$ and $(16,21,-7)_{L M N} \mathrm{nT}$. These magnetic field vectors form angles with the peak perpendicular velocity of $113^{\circ}$ and $64^{\circ}$ respectively; consequently the FTE has a stronger component of velocity along the background magnetic field in the inner boundary layer observed at Cluster $2\left(107 \mathrm{~km} \mathrm{~s}^{-1}\right)$ than along the magnetosheath field $\left(-95 \mathrm{~km} \mathrm{~s}^{-1}\right)$. Hence the lack of a bipolar $B_{N}$ signature at Cluster 2 does not appear to be due to a weaker component of velocity along the magnetic field. Therefore it appears likely that local compression of the magnetosphere as the FTE passes by is sufficient to force Cluster 2 deeper into the boundary layer structure, but not sufficient to produce a bipolar signature that can be observed as far from the magnetopause as Cluster 2.

As Clusters 3 and 2 both observed effects of the FTE without entering the FTE itself, its diameter can be identified as less than the separation of the two spacecraft along $\hat{N}(4800 \mathrm{~km})$. This is consistent with low-latitude estimates of $\sim 1 R_{E}$ (Saunders et al., 1984). Other FTEs were observed in the magnetosheath just before the 10:52 UT event (also highlighted in Fig. 8) for which there was either no signature (10:48.45 and 10:50.20 UT) or where a less significant signature (10:49.40 UT) was present. These FTEs were 


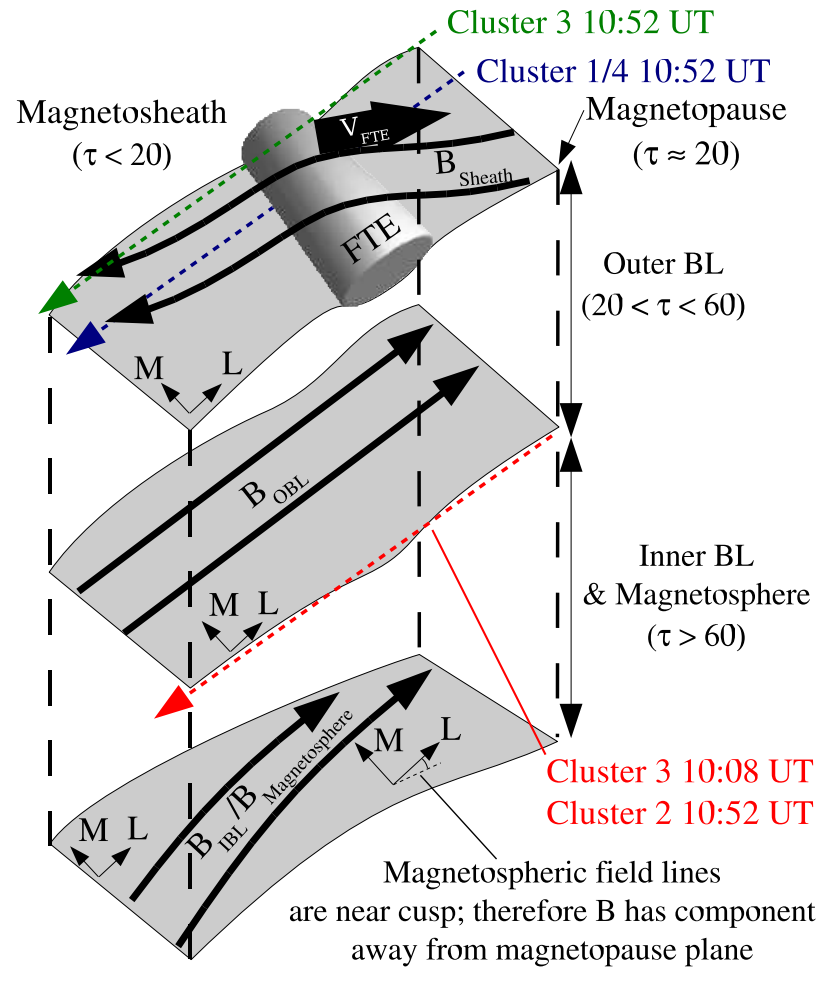

Fig. 10. A sketch of the boundary layer structure, and the relative paths of the spacecraft at 10:52 UT. Clusters 1 and 4 were in the magneosheath and passed through an FTE. Cluster 3 was also in the magnetosheath but further from the magnetopause and observed only field line draping. Cluster 2 was in the inner boundary layer, but entered the outer boundary layer as the FTE passed, leading to characteristic plasma and magnetic field signatures, but with no bipolar $B_{N}$ signature. Cluster 2 observed similar signatures at 10:52 UT to those observed by Cluster 3 at 10:08 UT.

presumably smaller than the 10:52 UT event.

Lockwood et al. (2001) concluded that a bipolar $B_{N}$ signature was absent when an FTE was observed near the wall of the interior cusp $\left(B_{Z}<0\right)$. Our observations are similar to their first "bipolar" signature; both were observed near the lip of the cusp, where $B_{Z} \approx 0$ (Fig. 14, Lockwood et al., 2001). Although we agree with their overall picture, we believe that the magnetic signature observed by Lockwood et al. (2001) was closer to those observed in the present study at 10:08 and 10:52 UT than to a traditional bipolar FTE signature. Our 10:52 UT event, with direct measurement of traditional magnetosheath FTE signatures, confirms that these less orthodox boundary layer signatures are also caused by FTEs.

\section{Conclusions}

The magnetopause transition parameter was used to reorder plasma and magnetic field observations throughout this complicated interval. This procedure clarified the boundary layer structure. Although transitions within this structure were not generally sharp, we split this structure into four regions (magnetosphere, an inner boundary layer, an outer boundary layer and the magnetosheath) and identified the magnetopause as the interface between the outer boundary layer and magnetosheath. After the outer three spacecraft had entered the magnetosheath, a series of FTEs was observed with clear plasma and bipolar $B_{N}$ signatures. At the same time as one of these FTEs passed (10:52 UT), the spacecraft within the magnetopause observed signatures consistent with moving deeper into the boundary layer structure. Without the benefit of simultaneous magnetosheath observations, this signature would most likely not have been identified as being related to an FTE, as there was no bipolar $B_{N}$ variation.

It is entirely possible that some of the earlier boundary layer entries (including 10:08 UT) observed by Clusters 1, 3 and 4 were due to passing FTEs forcing the boundary layer structure inwards, making it difficult to identify magnetospheric FTEs at high latitudes. Contrary to the low-latitude debate, which concentrated on alternative explanations for the magnetic field and plasma observations attributed to transient reconnection, this difficulty arises from the presence of the observed boundary layer structure.

Acknowledgements. The authors thank the PEACE, FGM, CIS and EFW operations teams for their work on the Cluster data, and the ACE SWEPAM and MAG teams and ACE Science Center for providing the ACE data. RCF was supported by a United Kingdom PPARC Studentship. We also thank the referee for helpful comments.

Topical Editor T. Pulkkinen thanks D. Sibeck for his help in evaluating this paper.

\section{References}

Balogh, A., Carr, C. M., Acuña, M. H., Dunlop, M. W., Beek, T. J., Brown, P., Fornaçon, K. H., Georgescu, E., Glassmeier, K. H., Harris, J., Musmann, G., Oddy, T., and Schwingenschuh, K.: The Cluster Magnetic Field Investigation: Overview of in-flight performance and initial results, Ann. Geophys., 19, 1207-1217, 2001,

SRef-ID: 1432-0576/ag/2001-19-1207.

Bosqued, J. M., Phan, T. D., Dandouras, I., Escoubet, C. P., Rème, H., Balogh, A., Dunlop, M. W., Alcaydé, D., Amata, E., Bavassano-Cattaneo, M. B., Bruno, R., Carlson, C., DiLellis, A. M., Eliasson, L., Formisano, V., Kistler, L. M., Klecker, B., Korth, A., Kucharek, H., Lundin, R., McCarthy, M., McFadden, J. P., Möbius, E., Parks, G. K., and Sauvaud, J. A.: Cluster observations of the high-latitude magnetopause and cusp: Initial results from the CIS ion instruments, Ann. Geophys., 19, 15451566, 2001,

SRef-ID: 1432-0576/ag/2001-19-1545.

Bryant, D. A. and Riggs, S.: At the edge of the Earth's magnetosphere: A survey by AMPTE-UKS, Phil. Trans. R. Soc. Lond. A., 328, 43-56, 1989.

Daly, P. W., Williams, D. J., Russell, C. T., and Keppler, E.: Particle signature of magnetic flux transfer events at the magnetopause, J. Geophys. Res., 86, 1628-1632, 1981.

Elphic, R. C.: Observations of flux transfer events: Are FTEs flux ropes, islands, or surface waves?, in Physics of Magnetic Flux Ropes, (Eds.) Russell, C. T., Priest, E. R., and Lee, L. C. 
Geophysical Monograph 58, 455-471, AGU, Washington D. C., 1990.

Elphic, R. C., Baumjohann, W., Cattell, C. A., Lühr, H., and Smith, M. F.: A search for upstream pressure pulses associated with flux transfer events: An AMPTE/ISEE case study, J. Geophys. Res., 99, 13 521-13 527, 1994.

Farrugia, C. J., Elphic, R. C., Southwood, D. J., and Cowley, S. W. H.: Field and flow perturbations outside the reconnected field line region in flux transfer events: Theory, Planet. Space Sci., 35, 227-240, 1987a.

Farrugia, C. J., Southwood, D. J., Cowley, S. W. H., Rijnbeek, R. P., and Daly, P. W.: Two-regime flux transfer events, Planet. Space Sci., 35, 737-744, 1987b.

Gustafsson, G., André, M., Carozzi, T., Eriksson, A. I., Fälthammar, C.-G., Grard, R., Holmgren, G., Holtet, J. A., Ivchenko, N., Karlsson, T., Khotyaintsev, Y., Klimov, S., Laakso, H., Lindqvist, P.-A., Lybekk, B., Marklund, G., Mozer, F., Mursula, K., Pedersen, A., Popielawska, B., Savin, S., Stasiewicz, K., Tanskanen, P., Vaivads, A., and Wahlund, J.-E.: First results of electric field and density observations by Cluster EFW based on initial months of operation, Ann. Geophys., 19, 1219-1240, 2001,

\section{SRef-ID: 1432-0576/ag/2001-19-1219.}

Haerendel, G., Paschmann, G., Sckopke, N., Rosenbauer, H., and Hedgecock, P. C.: The frontside boundary layer of the magnetosphere and the problem of reconnection, J. Geophys. Res., 83, 3195-3216, 1978.

Hapgood, M. A. and Bryant, D. A.: Re-ordered electron data in the low-latitude boundary layer, Geophys. Res. Lett., 17, 2043 2046, 1990.

Hapgood, M. A. and Bryant, D. A.: Exploring the magnetospheric boundary layer, Planet. Space Sci., 40, 1431-1459, 1992.

Hapgood, M. A. and Lockwood, M.: Rapid changes in LLBL thickness, Geophys. Res. Lett., 22, 77-80, 1995.

Heikkila, W. J.: Impulsive plasma transport through the magnetosphere, Geophys. Res. Lett., 9, 159-162, 1982.

Johnstone, A. D., Alsop, C., Burdge, S., Carter, P. J., Coates, A. J., Coker, A. J., Fazakerley, A. N., Grande, M., Gowen, R. A., Gurgiolo, C., Hancock, B. K., Narheim, B., Preece, A., Sheather, P. H., Winningham, J. D., and Woodliffe, R. D.: PEACE: a Plasma Electron And Current Experiment, Space Sci. Rev., 79, 351-398, 1997

Kawano, H., Kokubun, S., and Takahashi, K.: Survey of transient magnetic field events in the dayside magnetosphere, J. Geophys. Res., 97, 10 677-10 692, 1992.

Lanzerotti, L. J.: Comment on "Solar wind dynamic pressure variations and transient magnetospheric signatures", Geophys. Res. Lett., 16, 1197-1199, 1989.

Lee, L. C. and Fu, Z. F.: A theory of magnetic flux transfer at the Earth's magnetopause, Geophys. Res. Lett., 12, 105-108, 1985.

Lemaire, J. and Roth, M.: Penetration of solar wind plasma elements into the magnetosphere, J. Atmos. Terr. Phys., 40, 331335,1978

Lemaire, J., Rycroft, M. J., and Roth, M.: Control of impulsive plasma penetration of solar wind irregularities into the magnetosphere by the interplanetary magnetic field, Planet. Space Sci., 27, 47-57, 1979.

Lockwood, M.: Flux transfer events at the dayside magnetopause: Transient reconnection or magnetosheath dynamic pressure pulses?, J. Geophys. Res., 96, 5497-5509, 1991.

Lockwood, M. and Hapgood, M.: On the cause of a magnetospheric flux transfer event, J. Geophys. Res., 103, 26453-26 478, 1998.
Lockwood, M. and Hapgood, M. A.: How the magnetopause transition parameter works, Geophys. Res. Lett., 24, 373-376, 1997.

Lockwood, M., Fazakerley, A. N., Opgenoorth, H., Moen, J., van Eyken, A. P., Dunlop, M., Bosqued, J. M., Lu, G., Cully, C., Eglitis, P., McCrea, I. W., Hapgood, M. A., Wild, M. N., Stamper, R., Denig, W., Taylor, M., Wild, J. A., Provan, G., Amm, O., Kauristie, K., Pulkkinen, T., Strømme, A., Prikryl, P., Pitout, F., Balogh, A., Rème, H., Behlke, R., Hansen, T., Greenwald, R., Frey, H., Morley, S. K., Alcaydé, D., Blelly, P. L., Donova, E., Engebretson, M., Lester, M., Watermann, J., and Marcucci, M. F.: Coordinated Cluster and ground-based instrument observations of transient changes in the magnetopause boundary layer during an interval of predominantly northward IMF: Relation to reconnection pulses and FTE signatures, Ann. Geophys., 19, 1613-1640, 2001,

SRef-ID: 1432-0576/ag/2001-19-1613.

Lundin, R., Sauvaud, J. A., Rème, H., Balogh, A., Dandouras, I., Bosqued, J. M., Carlson, C., Parks, G. K., Möbius, E., Kistler, L. M., Klecker, B., Amata, E., Formisano, V., Dunlop, M., Eliasson, L., Korth, A., Lavraud, B., and McCarthy, M.: Evidence for impulsive solar wind plasma penetration through the dayside magnetopause, Ann. Geophys., 21, 457-472, 2003,

SRef-ID: 1432-0576/ag/2003-21-457.

McComas, D. J., Bame, S. J., Barker, P., Feldman, W. C., Phillips, J. L., Riley, P., and Griffee, J. W.: Solar Wind Electron Proton Alpha Monitor (SWEPAM) for the Advanced Composition Explorer, Space Sci. Rev., 86, 563-612, 1998.

Owen, C. J. and Cowley, S. W. H.: Heikkila's mechanism for impulsive plasma transport through the magnetosphere: A reexamination, J. Geophys. Res., 96, 5565-5574, 1991.

Owen, C. J., Fazakerley, A. N., Carter, P. J., Coates, A. J., Krauklis, I. C., Szita, S., Taylor, M. G. G. T., Travnicek, P., Watson, G., Wilson, R. J., Balogh, A., and Dunlop, M. W.: Cluster PEACE observations of electrons during magnetospheric flux transfer events, Ann. Geophys., 19, 1509-1522, 2001,

SRef-ID: 1432-0576/ag/2001-19-1509.

Paschmann, G., Haerendel, G., Papamastorakis, I., Sckopke, N., Bame, S. J., Gosling, J. T., and Russell, C. T.: Plasma and magnetic field characteristics of magnetic flux transfer events, J. Geophys. Res., 87, 2159-2168, 1982.

Rème, H., Aoustin, C., Bosqued, J. M., Dandouras, I., Lavraud, B., Sauvaud, J. A., Barthe, A., Bouyssou, J., Camus, T., Coeur-Joly, O., Cros, A., Cuvilo, J., Ducay, F., Garbarowitz, Y., Medale, J. L., Penou, E., Perrier, H., Romefort, D., Rouzaud, J., Vallat, C., Alcaydé, D., Jacquey, C., Mazelle, C., d’Uston, C., Möbius, E., Kistler, L. M., Crocker, K., Granoff, M., Mouikis, C., Popecki, M., Vosbury, M., Klecker, B., Hovestadt, D., Kucharek, H., Kuenneth, E., Paschmann, G., Scholer, M., Sckopke, N., Seidenschwang, E., Carlson, C. W., Curtis, D. W., Ingraham, C., Lin, R. P., McFadden, J. P., Parks, G. K., Phan, T., Formisano, V., Amata, E., Bavassano-Cattaneo, M. B., Baldetti, P., Bruno, R., Chionchio, G., DiLellis, A., Marcucci, M. F., Pallocchia, G., Korth, A., Daly, P. W., Graeve, B., Rosenbauer, H., Vasyliunas, V., McCarthy, M., Wilber, M., Eliasson, L., Lundin, R., Olsen, S., Shelley, E. G., Fuselier, S., Ghielmetti, A. G., Lennartsson, W., Escoubet, C. P., Balsiger, H., Friedel, R., Cai, J. B., Kovrazhkin, R. A., Papamastorakis, I., Pellat, R., Scudder, J., and Sonnerup, B.: First multispacecraft ion measurements in and near the Earth's magnetosphere with the identical Cluster Ion Spectrometry (CIS) experiment, Ann. Geophys., 19, 1303-1354, 2001,

SRef-ID: 1432-0576/ag/2001-19-1303. 
Rijnbeek, R. P. and Cowley, S. W. H.: Magnetospheric flux erosion events are flux transfer events, Nature, 309, 135-138, 1984.

Rijnbeek, R. P., Cowley, S. W. H., Southwood, D. J., and Russell, C. T.: A survey of dayside flux transfer events observed by ISEE1 and ISEE-2 magnetometers, J. Geophys. Res., 89, 786-800, 1984.

Roelof, E. C. and Sibeck, D. G.: Magnetopause shape as a bivariate function of interplanetary magnetic field $B_{Z}$ and solar wind dynamic pressure, J. Geophys. Res., 98, 21 421-21 450, 1993.

Russell, C. T. and Elphic, R. C.: Initial ISEE magnetometer results: Magnetopause observations, Space Sci. Rev., 22, 681-715, 1978.

Russell, C. T. and Elphic, R. C.: ISEE observations of flux transfer events at the dayside magnetopause, Geophys. Res. Lett., 6, 3336, 1979.

Sanny, J., Sibeck, D. G., Venturini, C. C., and Russell, C. T.: A statistical study of transient events in the outer dayside magnetosphere, J. Geophys. Res., 101, 4939-4952, 1996.

Saunders, M. A., Russell, C. T., and Sckopke, N.: Flux transfer events: Scale size and interior structure, Geophys. Res. Lett., 11, 131-134, 1984.

Scholer, M.: Magnetic flux transfer at the magnetopause based on single X-line bursty reconnection, Geophys. Res. Lett., 15, 291294, 1988.

Sckopke, N.: Plasma structure near the low-latitude boundary layer: A rebuttal, J. Geophys. Res., 96, 9815-9820, 1991.

Sibeck, D. G.: A model for the transient magnetospheric response to sudden solar wind dynamic pressure variations, J. Geophys. Res., 95, 3755-3771, 1990.

Sibeck, D. G.: Transient events in the outer magnetosphere: Boundary waves or flux transfer events?, J. Geophys. Res., 97, 40094026, 1992.

Sibeck, D. G. and Newell, P. T.: Pressure-pulse driven surface waves at the magnetopause: A rebuttal, J. Geophys. Res., 100, $21773-21778,1995$.

Sibeck, D. G. and Newell, P. T.: Reply, J. Geophys. Res., 101, 13 351-13 352, 1996.
Sibeck, D. G., Baumjohann, W., Elphic, R. C., Fairfield, D. H., Fennell, J. F., Gail, W. B., Lanzerotti, L. J., Lopez, R. E., Luehr, H., Lui, A. T. Y., MacLennan, C. G., McEntire, R. W., Potemra, T. A., Rosenberg, T. J., and Takahashi, K.: The magnetospheric response to 8-minute period strong-amplitude upstream pressure variations, J. Geophys. Res., 94, 2505-2519, 1989.

Smith, C. W., L'Heureux, J., Ness, N. F., Acuña, M. H., Burlaga, L. F., and Scheifele, J.: The ACE magnetic fields experiment, Space Sci. Rev., 86, 613-632, 1998.

Smith, M. F. and Curran, D. B.: On the correlation between a magnetopause penetration parameter and FTE occurrence, Ann. Geophys., 8, 579-582, 1990.

Smith, M. F. and Owen, C. J.: Temperature anisotropies in a magnetospheric FTE, Geophys. Res. Lett., 19, 1907-1910, 1992.

Song, P., Le, G., and Russell, C. T.: Observational differences between flux transfer events and surface waves at the magnetopause, J. Geophys. Res., 99, 2309-2320, 1994.

Song, P., Le, G., and Russell, C. T.: Comment on "Pressure-pulse driven surface waves at the magnetopause: a rebuttal", J. Geophys. Res., 101, 13 349-13 350, 1996.

Sonnerup, B. U. Ö.: On the stress balance in flux transfer events, J. Geophys. Res., 92, 8613-8620, 1987.

Southwood, D. J., Farrugia, C. J., and Saunders, M. A.: What are flux transfer events?, Planet. Space Sci., 36, 503-508, 1988.

Thompson, S. M., Kivelson, M. G., Khurana, K. K., Balogh, A., Rème, H., Fazakerley, A. N., and Kistler, L. M.: Cluster observations of quasi-periodic impulsive signatures in the dayside northern lobe: High-latitude flux transfer events?, J. Geophys. Res., 109A02, 213, doi:10.1029/2003JA010 138, 2004.

Vontrat-Reberac, A., Bosqued, J. M., Taylor, M. G. G. T., Lavraud, B., Fontaine, D., Dunlop, M. W., Laakso, H., CornilleauWerhin, N., Canu, P., and Fazakerley, A.: Cluster observations of the high-altitude cusp for northward interplanetary magnetic field: A case study, J. Geophys. Res., 108, 1346, doi:10.1029/2002JA009717, 2003. 